\title{
Knowledge of energy consumption
}

\author{
ROBERT J. WEBER and JAMES M. PRICE \\ Oklahoma State University, Stillwater, Oklahoma 74074
}

\begin{abstract}
Knowledge of energy consumption by various appliances was assessed. A paired-comparison scale of relative subjective energy consumption was established for the different appliances, and the resulting scale values were correlated with actual energy consumption by the same appliances. Two forms of energy consumption were assessed: continuous use over a short time interval and typical use over 1 year. The results indicated that the college student subjects did not possess very accurate information about appliance energy consumption. This may be an important finding because energy conservation efforts probably presuppose knowledge of relative energy consumption.
\end{abstract}

Effective energy conservation efforts are likely to presuppose knowledge of energy consumption rates. Because Americans consume about $22 \%$ of the country's total energy in their residences (Residential Energy Conservation, 1979), the consumer's knowledge of energy consumption is an important issue. In particular, residential conservation efforts are likely to be affected by knowledge of the energy consumption of different appliances.

We make the distinction between an appliance's electrical consumption in continuous usage for $1 \mathrm{~h}$ (measured in watt hours, Wh, numerically the same value as the appliance's wattage rating) and the same appliance's typical usage figure for 1 year (measured in kilowatt hours, $\mathrm{kWh}$ ). This is an important distinction because some appliances, say, a toaster, consume a great deal of energy while in operation (about $1,150 \mathrm{~W}$ ) but are not used for much total time over 1 year (about $39 \mathrm{kWh} /$ year for typical usage). In contrast, a 12-cu-ft refrigerator consumes energy at a lower rate (about $240 \mathrm{~W}$ ), but because it normally runs intermittently throughout every day of the year, it consumes much more electricity during the year (about $728 \mathrm{kWh}$ for typical usage). Our figures for actual continuous use over $1 \mathrm{~h}$ and for actual typical use over 1 year are based on Johannson (1975). Some additional example usage rates for 1 continuous hour/typical year in watt hours/kilowatt hours are as follows: clock $2 / 17$, dishwasher $122 / 363$, water heater $2,475 / 4,219$, and clothes dryer $4,856 / 933$. Clearly, an appliance's certified wattage rating may not give the kind of information required for effective conservation behavior.

\section{METHOD}

To assess knowledge of relative energy consumption by different appliances, we employed a paired-comparison scaling

Send reprint requests to Robert J. Weber, Psychology Department, Oklahoma State University, Stillwater, Oklahoma 74074. This research was supported in part by the Education Research Foundation and in part by the Institute for Energy Analysis, both of Oklahoma State University. procedure. The method was to present the names of 14 common appliances in all 91 possible pairs; each item in a pair was assigned randomly to the left or right position. Then from each name pair, each of 25 undergraduates picked the appliance that used the most energy. The resulting subjective scale values were then correlated with actual usage. Subjects performed the scaling under two instructional sets: first, for continuous hourly energy consumption, and second, for typical yearly consumption. These separate scales were also correlated.

\section{RESULTS}

The Pearson coefficients were as follows: $r$ (subjective hourly, actual hourly) $=.64$ and $r$ (subjective yearly, actual yearly) $=.52$. These correlations were significant $(p<.05)$, but they did not account for much of the variance. The $\mathrm{r}^{2}$ (subjective hourly, actual hourly) $=.41$; hence almost $60 \%$ of the variance was unaccounted for. The $\mathrm{r}^{2}$ (subjective yearly, actual yearly) $=.27$; that is, $73 \%$ of the variance was not accounted for. The highest correlation obtained was between the two subjective estimates, with $r$ (subjective hourly, subjective yearly) = .79. The lowest correlation was between actual continuous usage for $1 \mathrm{~h}$ and actual typical usage for 1 year: $\mathrm{r}($ actual hourly, actual yearly $)=.33$.

\section{DISCUSSION}

There are several possible interpretations of these findings that cannot be distinguished on the basis of the data. (1) The figures we used for actual usage may not be universally agreed on. There may be considerable variability in hourly wattage ratings for different brands or models of the same appliance. There may also be large variability in individual usage levels, so that the yearly figures would legitimately vary among users. (2) Our college student subjects may have limited experience paying utility bills, so they could not be expected to know very much about consumption. (3) Typically, there is no immediate feedback from an appliance to suggest its consumption rate. For this reason people do not know very much about consumption rates. In fact, the high correlation between subjective estimates of hourly and yearly consumption suggests that people have difficulty distinguishing between continuous use and typical use, even though they are not highly correlated. According to this view, what is needed is better, more immediate energy consumption feedback from our appliances. Each appliance should 
be rated not only for watts but for typical use. Ideally, each appliance should have a meter that would show present usage rate, accumulated use for the month and year, and, perhaps, accumulated use for the life of the appliance (like a car's odometer). With recent advances in integrated circuits and visual displays, such an ideal may soon be economically feasible.

Whatever interpretation is accepted, it is likely that knowledge of energy consumption will increase as appropriate feedback is provided (Seligman, Darley, \& Becker, 1978). Increased knowledge of consumption is probably a necessary condition for more frequent and effective conservation behavior. The results obtained indicate that present knowledge is not very extensive.

\section{REFERENCES}

Johannson, F. (Ed.), The consumer survival kit. Owings Mills Md: Maryland Center for Public Broadcasting, 1975.

Residential Energy Conservation (Vol. 1). Washington, D.C: Office of Technology Assessment, 1979.

Seligman, C., Darley, J., \& Becker, L. Behavioral approaches to residential energy conservation. Energy and Building, April 1978, pp. 325-337.

(Received for publication February 8, 1980.) 